\title{
Multiwavelength Light-Responsive Au/B-TiO2 Janus Micromotors
}

\section{Journal Article}

\section{Author(s):}

Jang, Bumjin; Hong, Ayoung (DD; Kang, Ha Eun; Alcantara, Carlos; Charreyron, Samuel (D); Mushtaq, Fajer; Pellicer, Eva; Büchel, Robert; Sort, Jordi; Lee, Sung Sik (1); Nelson, Bradley J.; Pané, Salvador

Publication date:

2017-06

Permanent link:

https://doi.org/10.3929/ethz-b-000185620

Rights / license:

In Copyright - Non-Commercial Use Permitted

Originally published in:

ACS Nano 11(6), https://doi.org/10.1021/acsnano.7b02177 


\section{Multi-Wavelength Light Responsive Au/B-TiO2 Janus}

\section{Micromotors}

Bumjin Jang, ${ }^{\dagger}$ Ayoung Hong, ${ }^{\dagger}$ Ha Eun Kang, ${ }^{\dagger}$ Carlos Alcantara, ${ }^{\dagger}$ Samuel Charreyron, ${ }^{\dagger}$ Fajer

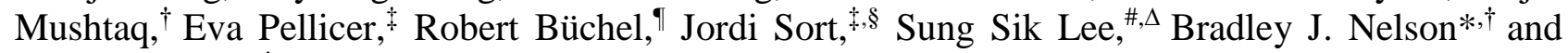
Salvador Pané $*, \dagger$

$\dagger$ Institute of Robotics and Intelligent Systems, ETH Zurich, Zurich, CH-8092, Switzerland

† Departament de Física, Universitat Autònoma de Barcelona, E-08193 Bellaterra, Spain

IParticle Technology Laboratory, Institute of Process Engineering, Department of Mechanical and

Process Engineering, ETH Zurich, Sonneggstrasse 3, CH-8092, Switzerland

§Institució Catalana de Recerca i Estudis Avançats (ICREA), Pg. Lluís Companys 23, E-08010

Barcelona, Spain

\#Department of Biology, Institute of Biochemistry, ETH Zurich, Otto-Stern-Weg 3, 8093 Zürich,

Switzerland

$\Delta$ Scientific Center for Optical and Electron Microscopy, ETH Zurich, Otto-Stern-Weg 3, 8093

Zürich, Switzerland

ABSTRACT: Conventional photocatalytic micromotors are limited to the use of specific wavelengths of light due to their narrow light-absorption spectrum, which limits their effectiveness for applications in biomedicine and environmental remediation. We present a multi-wavelength light responsive Janus micromotor consisting of a black $\mathrm{TiO}_{2}$ microsphere asymmetrically coated with a thin $\mathrm{Au}$ layer. The black $\mathrm{TiO}_{2}$ microspheres exhibit absorption ranges between 300 and 800 nm. The Janus micromotors are propelled by light, both in $\mathrm{H}_{2} \mathrm{O}_{2}$ solutions and in pure $\mathrm{H}_{2} \mathrm{O}$ over a broad range of wavelengths including UV, blue, cyan, green, and red light. An analysis of the particles' motion shows that the motor speed decreases with increasing wavelength, which has not 
been previously realized. A significant increase in motor speed is observed when exploiting the entire visible light spectrum ( $>400 \mathrm{~nm}$ ), suggesting a potential use of solar energy, which contains a great portion of visible light. Finally, stop-go motion is also demonstrated by controlling the visible light illumination, a necessary feature for the steerability of micro- and nanomachines.

KEYWORDS: micromotors, black $\mathrm{TiO}_{2}, \mathrm{Au} / \mathrm{B}-\mathrm{TiO}_{2}$ Janus micromotors, photocatalysis, multiwavelengths

Catalytic micromotors are autonomously propelled by harvesting fuel from their surrounding environment. ${ }^{1,2}$ While the propulsion direction must be controlled for precise locomotion, conventional catalytic micromotors show only random motion. Existing methods for directional control of catalytic micromotors include exploiting geometric anisotropies in motor design, ${ }^{3,4}$ using externally applied magnetic fields, ${ }^{5}$ or following topographical pathways ${ }^{6}$. In addition to controlling the direction of propulsion, the motors should have the ability to be throttled on-demand in order to achieve full motion control; a restriction of catalytic micromotors unless an additional chemical reaction or external stimulus is applied. ${ }^{7-9}$ The need for throttling makes photocatalytic materials attractive candidates because catalytic reactions can be controlled by adjusting the incident light intensity. ${ }^{10-12}$ For example, photocatalytic $\mathrm{TiO}_{2}$-based micromotors were shown to exhibit stop-go motion when cycling illumination between on and off states. ${ }^{13-16}$ Interestingly, researchers have shown that photocatalytic micromotors can also be designed to respond to light orientation. For example, Dai et al. have recently demonstrated that by changing the incident light orientation, photocatalytic Janus $\mathrm{Au} / \mathrm{TiO}_{2}$ nanowires can be precisely maneuvered along a desired trajectory. ${ }^{17}$ Despite these efforts, existing photocatalytic micromotors, such as $\mathrm{TiO}_{2-},{ }^{13-19} \alpha-\mathrm{Fe}_{2} \mathrm{O}_{3^{-}},{ }^{20-24} \mathrm{Cu}_{2} \mathrm{O}-,{ }^{25} \mathrm{WO}_{3},{ }^{26}$ and $\mathrm{BiOI}-{ }^{27}$ based motors, operate in narrow light spectra. This not only limits the efficient use of the entire available solar energy but also the range of applications for which such motors are useful. For example, ultraviolet (UV) light is widely used in existing photocatalytic propulsion ${ }^{13-19}$ or for protein imaging ${ }^{28}$. Yet, UV light is harmful to many living organisms ${ }^{29}$ including the photoreceptive cells of mammalian retina ${ }^{30-34}$. By the same token, 
E. coli, ${ }^{35}$ DNA,${ }^{36}$ mitochondria, ${ }^{37}$ and certain insects ${ }^{38}$ are all prone to damage by visible light in the wavelength range of $400-500 \mathrm{~nm}$. Therefore, it is necessary to develop systems that can be actuated by any portion of the available light spectrum. In this respect, black $\mathrm{TiO}_{2}\left(\mathrm{~B}-\mathrm{TiO}_{2}\right)$ can be seen as a good candidate because its light absorbance can be extended from UV light to the NIR region while retaining the advantages of $\mathrm{TiO}_{2}$, such as high photocatalytic activity, nontoxicity, semiconductor properties, and tunable surface wettability. ${ }^{39-42}$

In this work, we obtained $\mathrm{B}-\mathrm{TiO}_{2}$ microspheres by using a simple method, which includes a rapid thermal annealing on solvothermally synthesized $\mathrm{TiO}_{2}$ microspheres in ambient air condition. Janus micromotors, fabricated by half-coating a thin $\mathrm{Au}$ layer on the $\mathrm{B}-\mathrm{TiO}_{2}$ microspheres, propel not only in $\mathrm{H}_{2} \mathrm{O}_{2}$ solution, but also in pure water over a wide range of the light spectrum from UV to red light. We report that wavelength can be used as an additional parameter to control the speed of photocatalytic micromotors. In addition, we observed a dramatic increase in propulsion speed when exposing these micromotors to the entire range of visible light $(>400 \mathrm{~nm})$. Compared to other photocatalytic micromachines, the reported Janus micromotors can be used for a larger range of applications due to their higher photocatalytic activity over the entire spectrum of UV and visible light.

\section{RESULTS AND DISCUSSION}

Fabrication and characterization of $\mathrm{Au} / \mathrm{B}-\mathrm{TiO}_{2}$ Janus micromotors. The fabrication of $\mathrm{Au} / \mathrm{B}-\mathrm{TiO}_{2}$ micromotors is illustrated in Figure 1a. Briefly, solvothermally synthesized $\mathrm{TiO}_{2}$ microspheres were thermally annealed in ambient air condition at $400{ }^{\circ} \mathrm{C}$ with a rapid ramp-up rate of $75{ }^{\circ} \mathrm{C} / \mathrm{min}$, leading to the colorization of $\mathrm{TiO}_{2}$. Then, the $\mathrm{B}-\mathrm{TiO}_{2}$ microspheres were half-coated with evaporated gold. More details on fabrication can be found in experimental methods section. Figure $1 \mathrm{~b}$ shows a scanning electron microscope (SEM) image of a $\mathrm{Au} / \mathrm{B}-\mathrm{TiO}_{2}$ microsphere with a diameter of $\sim 3.5 \mu \mathrm{m}$ (see Figure 1b (i)). A visible distinction between the two hemispheres can be attributed to the two different materials that comprise the microsphere, indicating a Janus-like 
structure. This information was further validated using energy-dispersive X-ray spectroscopy (EDX) mapping. EDX signals from $\mathrm{Ti}$ and $\mathrm{O}$ suggest the presence of $\mathrm{TiO}_{2}$ (see Figure $1 \mathrm{~b}$ (ii) and (iii)), while $\mathrm{Au}$ is only detected on one hemisphere (see Figure 1b (iv)). Structural characterization of assynthesized $\mathrm{TiO}_{2}$ and $\mathrm{B}-\mathrm{TiO}_{2}$ was performed using X-ray diffraction (XRD) (Figure S1). The XRD pattern of as-synthesized $\mathrm{TiO}_{2}$ reveals broad halos of low intensity corresponding to an amorphous microstructure. In contrast, the XRD pattern of $\mathrm{B}-\mathrm{TiO}_{2}$ displays narrower peaks with higher intensities, which can be assigned to the crystalline anatase phase of titania. Chemical states of B$\mathrm{TiO}_{2}$ and as-synthesized $\mathrm{TiO}_{2}$ were investigated using X-ray photoelectron spectroscopy (XPS). Compared to as-synthesized $\mathrm{TiO}_{2}$, the deconvoluted $\mathrm{Ti} 2 \mathrm{p}$ spectrum of $\mathrm{B}-\mathrm{TiO}_{2}$ shows additional peaks at $457 \mathrm{eV}$ and $463 \mathrm{eV}$, which can be assigned to $2 \mathrm{p}_{3 / 2}$ and $2 \mathrm{p}_{1 / 2}$, respectively, of the $\mathrm{Ti}^{3+}$ (Figure S2). According to Jiang et al., this might indicate the occurrence of oxygen vacancies. ${ }^{43}$ Synthesis of $\mathrm{B}-\mathrm{TiO}_{2}$ requires certain optimal conditions of pressure, gas flow, and temperature, which are determined according to the type of precursors used to synthesize $\mathrm{TiO}_{2}{ }^{40}$ While $\mathrm{B}-\mathrm{TiO}_{2}$ nanoparticles have been extensively investigated, studies on $\mathrm{B}-\mathrm{TiO}_{2}$ microparticulates are scarce. ${ }^{44}$, ${ }^{45} \mathrm{NB}$ : The method reported here for the synthesis of $\mathrm{B}-\mathrm{TiO}_{2}$ microparticles is simpler compared to previously reported methods. The light absorption properties of as-synthesized $\mathrm{TiO}_{2}$ and $\mathrm{B}-\mathrm{TiO}_{2}$ were also investigated. Color differences between as-synthesized $\mathrm{TiO}_{2}$ and $\mathrm{B}-\mathrm{TiO}_{2}$ were visible to naked eye (Figure 1c). As-synthesized $\mathrm{TiO}_{2}$ exhibits a white color, which implies no absorption of visible light (Figure 1c (i)). B- $\mathrm{TiO}_{2}$ particles are dark brown, indicating that they absorb certain wavelengths of the visible light spectrum (Figure $1 \mathrm{c}(\mathrm{ii})$ ). ${ }^{40}$ The absorbance of as-synthesized $\mathrm{TiO}_{2}$ and $\mathrm{B}-\mathrm{TiO}_{2}$ powders was measured by diffuse reflectance spectrum (DRS). The results for $\mathrm{TiO}_{2}$ showed a narrow region of absorbance in the UV region $(300-380 \mathrm{~nm})$ in Figure $1 \mathrm{~d}$ with the band gap of $\sim 3.23 \mathrm{eV}$ in Figure $\mathrm{S} 3$. In contrast, results for $\mathrm{B}-\mathrm{TiO}_{2}$ showed a significantly broader region of absorbance covering the entire measured spectrum $(300-800 \mathrm{~nm})$ in Figure $1 \mathrm{~d}$ and lowered band gap ( $1.75 \mathrm{eV})$ in Figure $\mathrm{S} 3 . \mathrm{B}-\mathrm{TiO}_{2}$ shows a wider absorbance and lowered band gap, compared to the absorbance $(300-650 \mathrm{~nm})$ and band gap $(1.85 \mathrm{eV})$ of BiOI. ${ }^{46}$ 
This suggests that the photocatalytic activity of $\mathrm{B}-\mathrm{TiO}_{2}$ is not limited to UV illumination but can also be triggered by visible light. ${ }^{40} \mathrm{NB}$ : We found the color of $\mathrm{B}^{-\mathrm{TiO}_{2}}$ changes from beige to black and a corresponding increase in light absorption for longer wavelengths as the ramp-up rate of the annealing process increased (Figure S4). These results suggest that the ramp-up rate plays an important role in generating oxygen vacancies.

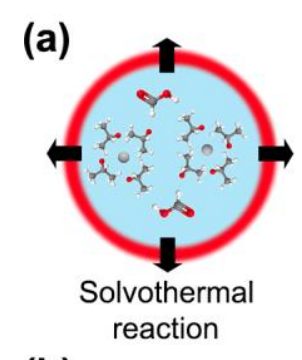

(b)

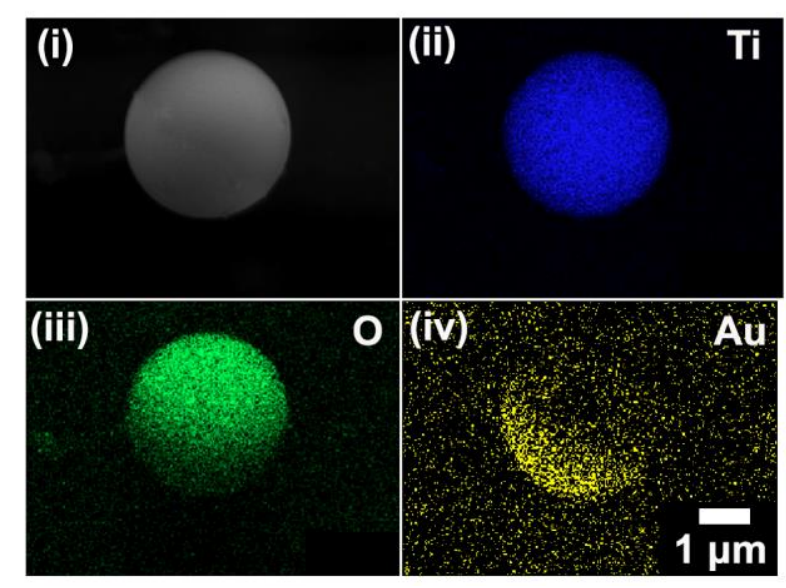

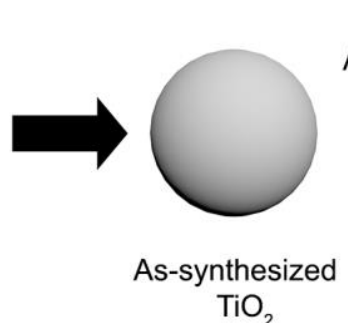

$\mathrm{TiO}_{2}$

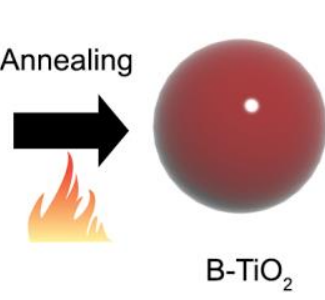

(c)

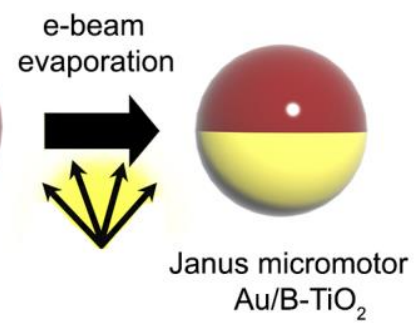

$\mathrm{Au} / \mathrm{B}-\mathrm{TiO}_{2}$

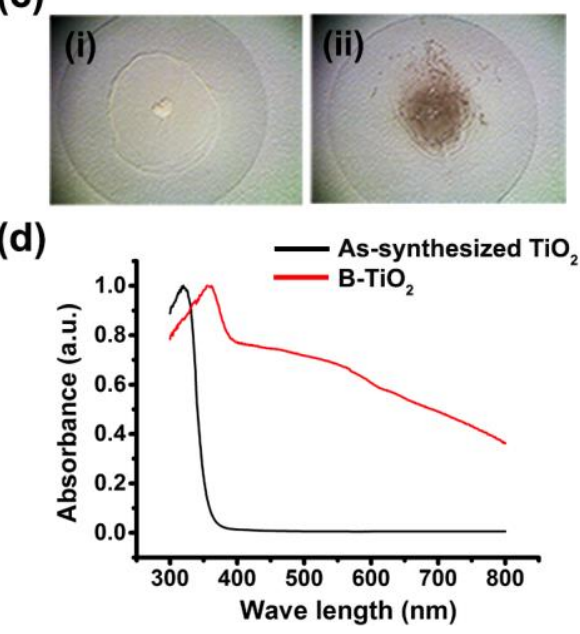

Figure 1. Synthesis and material characterization of $\mathbf{A u} / \mathbf{B}-\mathbf{T i O}_{2}$ Janus micromotors. (a) Schematic showing the synthesis of $\mathrm{Au} / \mathrm{B}-\mathrm{TiO}_{2}$ Janus micromotors. (b) The SEM and corresponding EDX images of a $\mathrm{Au} / \mathrm{B}-\mathrm{TiO}_{2}$ Janus micromotor: (i) The SEM image of a $\mathrm{Au} / \mathrm{B}-\mathrm{TiO}_{2}$ Janus micromotor, and the EDX images of (ii) $\mathrm{Ti}$, (iii) $\mathrm{O}$, and (iv) $\mathrm{Au}$ elements, respectively. (c) Images of microspheres: (i) as-synthesized $\mathrm{TiO}_{2}$ and (ii) $\mathrm{B}^{-\mathrm{TiO}_{2}}$ on glass substrates. (d). DRS spectrum of the as-synthesized $\mathrm{TiO}_{2}$ (black line) and $\mathrm{B}-\mathrm{TiO}_{2}$ (red line).

The motion of $\mathrm{Au} / \mathrm{B}_{-} \mathrm{TiO}_{2}$ Janus micromotors driven by full visible light. We

adopt the model proposed by previous studies to illustrate the motion of our micromotors. ${ }^{16,26}$ Similar to conventional catalytic Janus micromotors, ${ }^{47,} 48$ the motion of photocatalytic micromotors ${ }^{13,16}$ is driven by the decomposition of a fuel at the interface between the motor and solution, but only in the presence of light. $\mathrm{TiO}_{2}$ absorbs photons with energies equal to or higher than the energy of its bandgap, which in turn creates electron-hole pairs. The electrons are rapidly 
transferred to the Au layer, which serves as an electron sink and favors the separation of electronhole pairs. The remaining holes in $\mathrm{TiO}_{2}$ decompose hydrogen peroxide molecules $\left(\mathrm{H}_{2} \mathrm{O}_{2}\right)$ to molecular oxygen $\left(\mathrm{O}_{2}\right)$ and protons $\left(\mathrm{H}^{+}\right)$(Figure 2a). On the Au hemisphere, protons are reduced to molecular hydrogen $\left(\mathrm{H}_{2}\right)$. Due to a proton deficiency the protons migrate from the naked $\mathrm{TiO}_{2}$ surface to the Au side. This proton movement is known as self-electroosmosis flow and causes the micromotor to propel; note that the nature of the metal coating may affect the magnitude of the selfelectroosmosis flow, resulting in differences in motor speed. For example, Dong et al., observed higher speeds with $\mathrm{Au} / \mathrm{TiO}_{2}$ micromotors than with $\mathrm{Ni} / \mathrm{TiO}_{2} .{ }^{16}$

We monitored the motion of $\mathrm{Au} / \mathrm{B}-\mathrm{TiO}_{2}$ Janus micromotors driven by the full visible light spectrum $(\lambda>400 \mathrm{~nm})$. To ensure that the motion was not initiated by UV wavelengths, illumination from a $120 \mathrm{~W}$ mercury light source was filtered using a $400 \mathrm{~nm}$ high-pass filter. The trajectories of two moving $\mathrm{Au} / \mathrm{B}-\mathrm{TiO}_{2}$ Janus micromotors in 3 wt $\% \mathrm{H}_{2} \mathrm{O}_{2}$ show noticeable displacements of $\sim 59 \mu \mathrm{m}$ over $18 \mathrm{sec}$ (see Figure 2b (i) and Movie S1). In a control experiment, $\mathrm{Au} / \mathrm{TiO}_{2}$ Janus micromotors experienced only small and seemingly random displacements of $\sim 2 \mu \mathrm{m}$ over $33 \mathrm{sec}$, which can be attributed to Brownian motion (Figure 2b (ii) and Movie S1). These significantly higher displacement, approximately 30 times of $\mathrm{Au} / \mathrm{B}-\mathrm{TiO}_{2}$ Janus micromotors compared to $\mathrm{Au} / \mathrm{TiO}_{2}$, corroborated the photocatalytic nature of $\mathrm{Au} / \mathrm{B}-\mathrm{TiO}_{2}$ particle propulsion rather than thermophoretic effect by the surface plasmon resonance of the Au layer. The differences in motion can be explained by the differences in light absorption between $\mathrm{TiO}_{2}$ and $\mathrm{B}-\mathrm{TiO}_{2}$, as discussed earlier (see Figure 1d). While the absorption of as-synthesized $\mathrm{TiO}_{2}$ microspheres is negligible above $400 \mathrm{~nm}$, the absorption range of $\mathrm{B}-\mathrm{TiO}_{2}$ occurs over the entire visible wavelength spectrum $(400-800 \mathrm{~nm})$.

The motion of $\mathrm{Au} / \mathrm{B}-\mathrm{TiO}_{2}$ Janus micromotors was further characterized in various $\mathrm{H}_{2} \mathrm{O}_{2}$ concentrations $(0,0.03,0.3$, and $3 \mathrm{wt} \%)$. Figure $2 \mathrm{c}$ shows that the motor speed increases as the concentration of $\mathrm{H}_{2} \mathrm{O}_{2}$ increases, which is consistent with conventional catalytic motors. ${ }^{49-52} \mathrm{~A}$ 
larger concentration in $\mathrm{H}_{2} \mathrm{O}_{2}$ results in a higher decomposition rate at the $\mathrm{TiO}_{2}$ hemisphere. ${ }^{47,48}$ As a result, a higher proton gradient develops around the motor, which causes an increase in the motor speed. We note that the maximum speed observed was $30.1 \pm 8.71 \mu \mathrm{m} / \mathrm{s}$ in 3 wt $\% \mathrm{H}_{2} \mathrm{O}_{2}$, which is relatively higher than the speeds reported for Au/Pt bimetallic nanomotors $(\sim 20 \mu \mathrm{m} / \mathrm{s}$ at 5 wt $\%$ $\left.\mathrm{H}_{2} \mathrm{O}_{2}\right) .{ }^{53}$ Additionally, we achieved reasonable speeds at low concentrations of $\mathrm{H}_{2} \mathrm{O}_{2}(10.8 \pm 3.41$ $\mu \mathrm{m} / \mathrm{s}$ in $0.03 \mathrm{wt} \% \mathrm{H}_{2} \mathrm{O}_{2}$ ), which is promising for potential biological applications.

Given that more photons generate more electron-hole pairs in $\mathrm{TiO}_{2}$ and, therefore, increase the rate of $\mathrm{H}_{2} \mathrm{O}_{2}$ decomposition, the motor speed can also be modulated by the incident photon flux $(\Phi)$, which is itself proportional to the incident light intensity $(I)$ as shown in equation (1).

$$
I=\Phi \frac{h c}{\lambda}
$$

where $h, c, \lambda$ denote the Planck constant, speed of light, and wavelength of the incident light, respectively.

Various light intensities of $2.1,4.0,9.5$, and $20.4 \mathrm{~W} / \mathrm{cm}^{2}$ were employed to study the effect of light intensity on motor speed at a constant $\mathrm{H}_{2} \mathrm{O}_{2}$ concentration of $3 \mathrm{wt} \%$. Figure $2 \mathrm{~d}$ shows that the motor speed is dependent on the light intensity. The modulation of motor speed by light intensity has been considered as one of the figures of merit in photocatalytically driven micromotors when compared to conventional catalytic micromotors. ${ }^{14-17,19}$ 
(a)

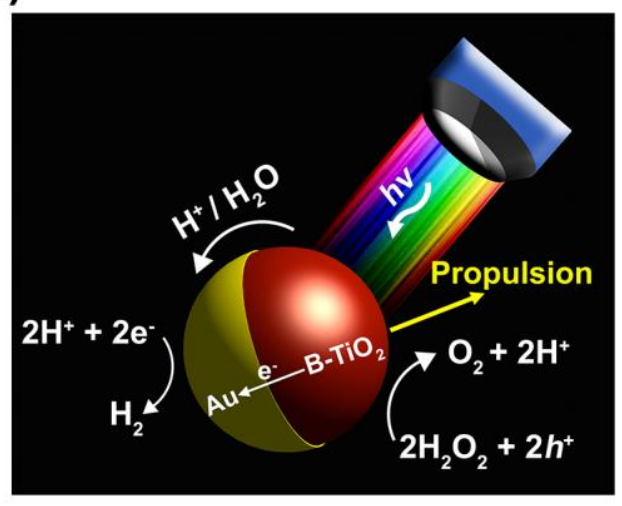

(c)

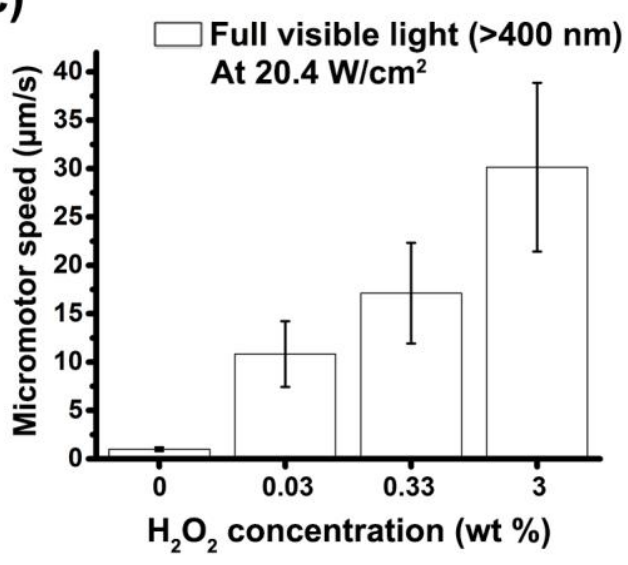

(b)

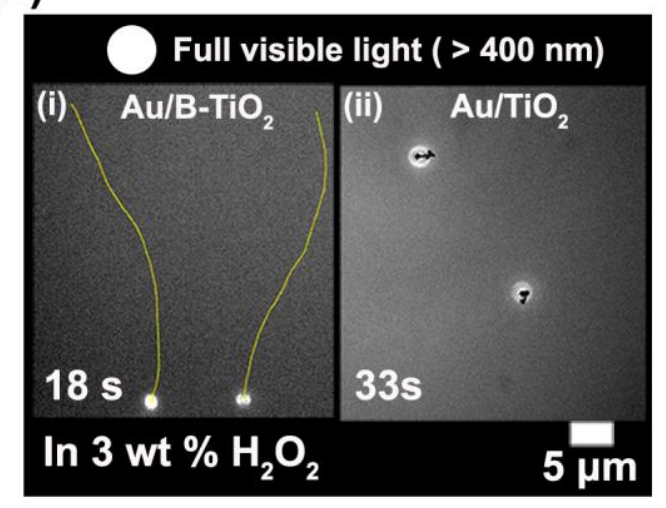

(d)

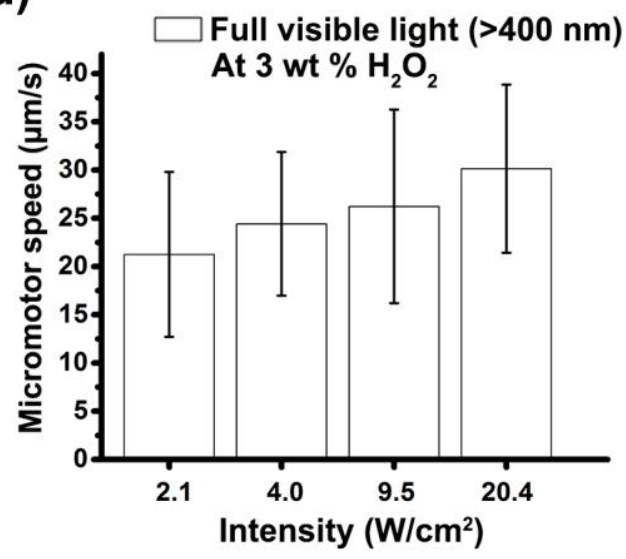

Figure 2. Full visible light (> $400 \mathrm{~nm}$ ) driven Au/B-TiO2 Janus micromotors. (a) A schematic of the propulsion mechanism of $\mathrm{Au} / \mathrm{B}-\mathrm{TiO}_{2}$ Janus micromotors, proposed based on previous studies. ${ }^{16,26}$ (b) Trajectories of (i) $\mathrm{Au} / \mathrm{B}-\mathrm{TiO} 2$ Janus micromotors over $18 \mathrm{sec}$ and (ii) $\mathrm{Au} / \mathrm{TiO}_{2}$ Janus micromotors (control sample) over $33 \mathrm{sec}$. (c) $\mathrm{The}_{\mathrm{effect}}$ of $\mathrm{H}_{2} \mathrm{O}_{2}$ concentration on the motor speed at the visible light intensity of $20.4 \mathrm{~W} / \mathrm{cm}^{2}$. The recorded speeds represent the average speeds from at least 14 samples per concentration. (d) The effect of visible-light intensity on the motor speed at $3 \mathrm{wt} \%$ $\mathrm{H}_{2} \mathrm{O}_{2}$. The recorded speeds represent the average speeds from at least 33 samples at each intensity.

\section{Motion of the $\mathrm{Au} / \mathrm{B}-\mathrm{TiO}_{2}$ Janus micromotors driven by various narrow-band light}

spectra. Our motion experiments of $\mathrm{Au} / \mathrm{B}-\mathrm{TiO}_{2}$ Janus particles under full visible light suggest that these micromotors should show superior performance when powered by solar energy, which contains a great portion of visible light ( $47 \%$ of the total solar energy). An additional benefit of these micromotors is their versatility. Some applications call for the restriction or exclusive use of certain wavelengths. For example, blue light $(400-500 \mathrm{~nm})$ is harmful to mammalian retinas, ${ }^{30-34}$ mitochondria, ${ }^{37}$ E. coli, ${ }^{35}$ and some species of insects, ${ }^{38}$ and should, therefore, be avoided in applications containing specific organelles, cells or organisms. UV light damages many living 
$\operatorname{organisms}^{29}$ but can be used selectively to eradicate bacteria, ${ }^{54,55}$ or to detect/visualize UVfluorescent proteins. ${ }^{28}$ To date, only a few types of materials $\left(\mathrm{TiO}_{2},{ }^{13-19} \mathrm{Fe}_{2} \mathrm{O}_{3},{ }^{20-24} \mathrm{Cu}_{2} \mathrm{O}^{25}, \mathrm{WO}_{3},{ }^{26}\right.$ and $\mathrm{BiOI}^{27}$ ) have been used in photocatalytic micromotors. However, they all suffer from limited absorption bands, which may preclude their use in several applications. In contrast, the wide illumination spectrum over which $\mathrm{Au} / \mathrm{B}-\mathrm{TiO}_{2}$ operate makes these micromotors useful for a wide variety of biomedical and environmental remediation applications.

Our micromotors were driven in 3 wt $\% \mathrm{H}_{2} \mathrm{O}_{2}$ under five different narrow-banded regions of the light spectrum: UV (360-370 nm), blue $(420-440 \mathrm{~nm})$, cyan $(460-495 \mathrm{~nm})$, green $(540-550 \mathrm{~nm})$, and red $(590-650 \mathrm{~nm})$. We observed that the micromotors were propelled, regardless of the illumination spectrum, but with increasing speed as the wavelength of the light decreased (see the trajectories in Movie S2). In contrast to previously reported photocatalytic micromotors whose speed can be only modulated by light intensity, our micromotors exhibit an additional degree of freedom as their speed can be also controlled by the light wavelength. Furthermore, we characterized the effect of $\mathrm{H}_{2} \mathrm{O}_{2}$ concentration on motor speed for each illumination spectrum. Similar to the results obtained with the full visible spectrum, the motor speed consistently increased with an increased $\mathrm{H}_{2} \mathrm{O}_{2}$ concentration (see Figure 3a-e).

The speed of the micromotors in different illumination conditions was plotted to comprehensively study the effect of wavelength on motor speed. Micromotor speed increased linearly with the incident photon flux (see Figure 2d). The incident photon flux was calculated using equation (1) for five different illumination spectra; the intensities measured by an optic power meter were 1.14, 1.80, 2.56, 2.46, and $1.61 \mathrm{~W} / \mathrm{cm}^{2}$, and the corresponding photon fluxes can be computed as $3.47 \times 10^{-2}$, $6.47 \times 10^{-2}, 1.02 \times 10^{-1}, 1.12 \times 10^{-1}$, and $8.35 \times 10^{-2} \mathrm{~mol} /\left(\mathrm{m}^{2} \mathrm{~s}^{1}\right)$, for $\mathrm{UV}$, blue, cyan, green and red light, respectively. The motor speed was normalized by the calculated proton flux and plotted as a function of the incident wavelength in Figure 3f. This normalization step did not change the decreasing exponential trend of motor speed with increasing wavelength (see Figure S5). The trend can be explained by examining the light absorption spectrum of $\mathrm{B}-\mathrm{TiO}_{2}$. As shown in Figure $1 \mathrm{~d}$, the 
light absorption of $\mathrm{B}-\mathrm{TiO}_{2}$ decreases with increasing wavelength, which results in the generation of fewer electron-hole pairs and, subsequently, a decrease in $\mathrm{H}_{2} \mathrm{O}_{2}$ decomposition. Consequently, the motor speed decreases because of a reduced proton flow around the motor. In addition to the light absorption factor, faster surface recombination may cause a decrease in motor speed. ${ }^{56}$ The normalized motor speed/photon flux can be interpreted as the quantum efficiency (QE) of our system, as QE is defined as the ratio of input energy to output energy. In briefly summarizing, Figure $3 \mathrm{f}$ shows that the effect of the concertation of $\mathrm{H}_{2} \mathrm{O}_{2}$ and wavelengths on the motor speed; motor speed increases as the concentration of $\mathrm{H}_{2} \mathrm{O}_{2}$ increases, but decreases as the wavelength increases.

(a)

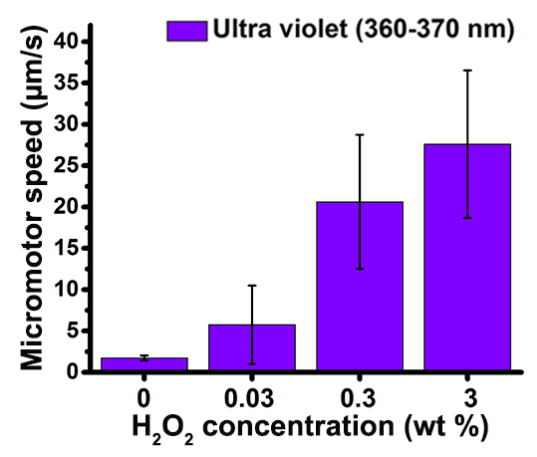

(d)

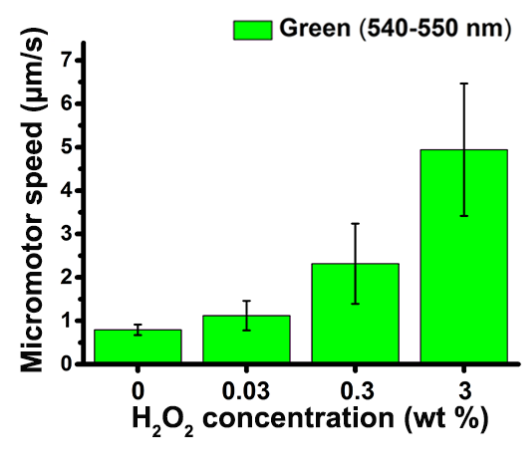

(b)

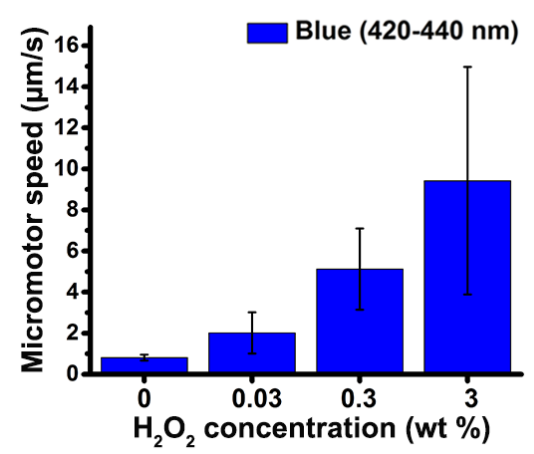

(e)

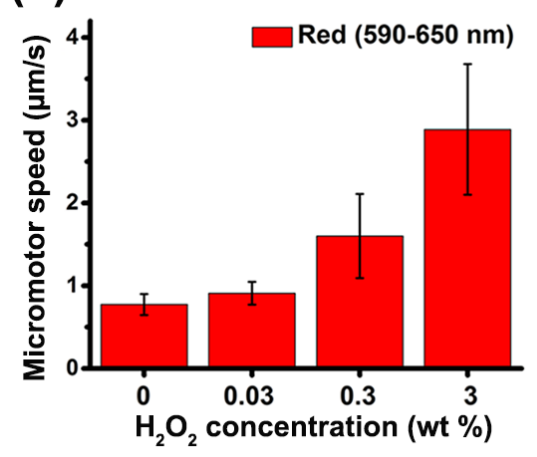

(c)

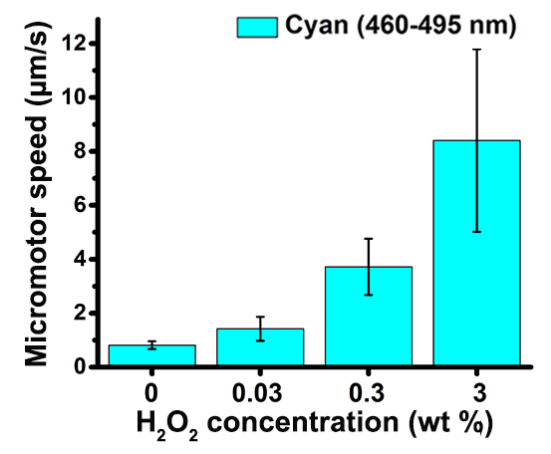

(f)

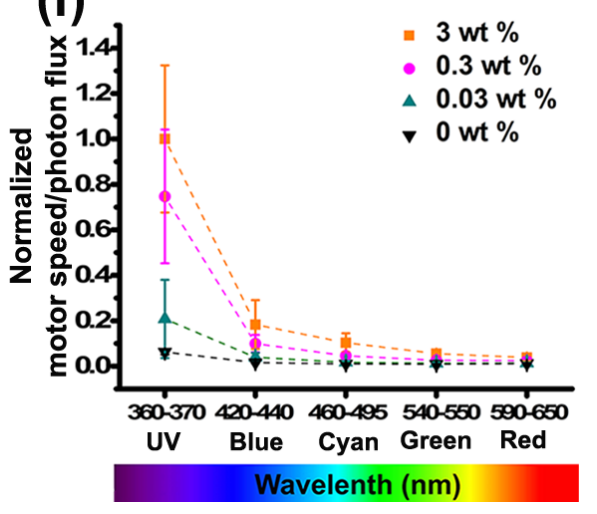

Figure 3. Motor speeds, actuated by five different narrow-band illumination at various $\mathrm{H}_{2} \mathrm{O}_{2}$ concentrations. (a)-

(e) Micromotor speed as a function of $\mathrm{H}_{2} \mathrm{O}_{2}$ concentration for UV (360 - $370 \mathrm{~nm}$ ), blue (420 - $\left.440 \mathrm{~nm}\right)$, cyan (460 - 495 $\mathrm{nm})$, green $(540-550 \mathrm{~nm})$, and red (590 - $650 \mathrm{~nm})$ light, respectively. All recorded speeds were obtained by averaging the speeds of at least eight samples per condition. (f) Normalized speed/photon flux as a function of wavelength at various $\mathrm{H}_{2} \mathrm{O}_{2}$ concentrations. 


\section{Microscopic motion analysis of $\mathrm{Au} / \mathrm{B}^{-\mathrm{TiO}_{2}}$ Janus micromotors driven by various light}

spectra in pure water $\left(\mathrm{H}_{2} \mathrm{O}\right)$. The measured speed of $\mathrm{Au} / \mathrm{B}-\mathrm{TiO}_{2}$ micromotors dropped to nearzero values in pure water regardless of the light used (Figure $2 \mathrm{c}$ and 3 ). In order to clarify whether the low speed of the micromotors can be solely attributed to Brownian motion, the mean-square displacements (MSD) of the particles under different conditions were calculated using equation $(2) .{ }^{57}$

$\operatorname{MSD}(\Delta t) \equiv<\left[\mathbf{r}(t)-\mathbf{r}\left(t_{0}\right)\right]^{2}>$

where $\mathbf{r}(t)=(x(t), y(t))$ is the particle position at time $t$ and $r\left(t_{0}\right)$ is the reference position.

To obtain high-fidelity MSD curves, the MSDs were obtained from the trajectories of least 14 particles, recorded for $\sim 24 \mathrm{sec}$ at $20 \mathrm{fps}$. Also, the maximum time interval $\Delta t$ of MSD plot was set to $2 \mathrm{sec}$, corresponding roughly to $10 \%$ of the total recording time.

The translational diffusivity $\left(D_{t}\right)$ and translational speed $(v)$ were extracted by fitting the MSD curves with the quadratic function shown in equation (3).

$\operatorname{MSD}(\Delta t)=4 D_{t} \Delta t+v^{2} \Delta t^{2}$

For comparison, the theoretical diffusivity for a particle in a diameter of $3.5 \mu \mathrm{m}$ was also calculated, using the Stokes-Einstein relation (4).

$D_{t 0}=\frac{K_{b} T}{6 \pi \eta r}$

where $D_{t 0}=$ theoretical diffusivity, $k_{B}=$ Boltzmann constant, $T=$ Temperature, $\eta=$ Viscosity of water, and $r=$ Radius of the particle.

The averaged MSD values and the corresponding quadratic fits are shown in Figure 4a. The fitted values are summarized in Table 1 . As expected, pure Brownian motion of the $\mathrm{Au} / \mathrm{B}-\mathrm{TiO}_{2}$ Janus micromotors is observed in the absence of light, which can be characterized by the low speed and a near linear MSD curve (Figure 4a). Compared to the theoretical diffusivity $\left(D_{t 0}\right)$, our experimental diffusivity $\left(D_{t}\right)$ is 2.78 times lower. We also used the parameters provided in Dong et $a l .{ }^{16}$ to estimate their theoretical diffusivity. We found that their $D_{t o} / D_{t}$ ratio is approximately the 
same as herein reported. The low ratio can be explained by the interaction of the Janus motors with the underlying substrate.

Under different illumination spectra, the speeds are notably higher than without illumination (Table 1), and the MSD curves (inset in Figure 4a) show a quadratic response to $\Delta t$, which is a clear sign that the particle motion is electroosmotically driven by splitting water rather than Brownian motion, as illustrated in Figure $4 \mathrm{~b}$. The recorded motor speed ( $v$ ) of $\mathrm{Au} / \mathrm{B}-\mathrm{TiO}_{2}$ Janus micromotors showed an increase with a decrease in wavelength (see the trajectories in Movie S3). This trend is similar to the results obtained with $\mathrm{H}_{2} \mathrm{O}_{2}$ in Figure $3 \mathrm{f}$ and can be explained by examining the light absorption spectrum of the as-synthesized $\mathrm{B}-\mathrm{TiO}_{2}$ particles, as discussed above. In addition, similar to experiments in $\mathrm{H}_{2} \mathrm{O}_{2}$, the micromotors propelled in pure water under full visible light showed faster propulsion with an average speed of $0.54 \mu \mathrm{m} / \mathrm{s}$ compared to the speeds of $0.08,0.16,0.23$ $\mu \mathrm{m} / \mathrm{s}$ for red, green, and blue illumination, respectively. The faster motor speed under full visible light compared to other narrow-banded regions of the light spectrum is due to the higher photon flux of full visible light compared to sectioned ones; $3.47 \times 10^{-2}, 6.47 \times 10^{-2}, 1.02 \times 10^{-1}, 1.12 \times$ $10^{-1}$, and $8.35 \times 10^{-2}$, and $1.1 \mathrm{~mol} /\left(\mathrm{m}^{2} \mathrm{~s}^{1}\right)$ are the used photon fluxes of $\mathrm{UV}$, blue, cyan, green, red light, and full visible light ( $>400 \mathrm{~nm}$ ), respectively.

For comparison, control experiments using $\mathrm{Au} / \mathrm{TiO}_{2}$ micromotors were conducted in the same manner, and MSD and speeds are plotted and summarized in Supporting Figure S6 and Table $\mathrm{S} 1$, respectively. We found that $\mathrm{Au} / \mathrm{TiO}_{2}$ Janus micromotors did not show significant differences in MSD and speeds among different visible light spectra and in the absence of light (see the trajectories in Movie S4). In contrast, a relatively large MSD was observed for $\mathrm{Au} / \mathrm{TiO}_{2}$ micromotors when they were exposed to UV light as $\mathrm{TiO}_{2}$ absorbs in this region (Figure S6 and Table S1). The speed of $\mathrm{Au} / \mathrm{TiO}_{2}$ micromotors under UV illumination is much slower than that of $\mathrm{Au} / \mathrm{B}-\mathrm{TiO}_{2}$. Considering that the photocatalytic efficiency of amorphous $\mathrm{TiO}_{2}$ is generally lower than of anatase $\mathrm{TiO}_{2},{ }^{58}$ it is expected that the $\mathrm{Au} / \mathrm{TiO}_{2}$ Janus micromotors with amorphous $\mathrm{TiO}_{2}$ exhibit lower motility than the $\mathrm{Au} / \mathrm{B}-\mathrm{TiO}_{2}$ Janus micromotors. 

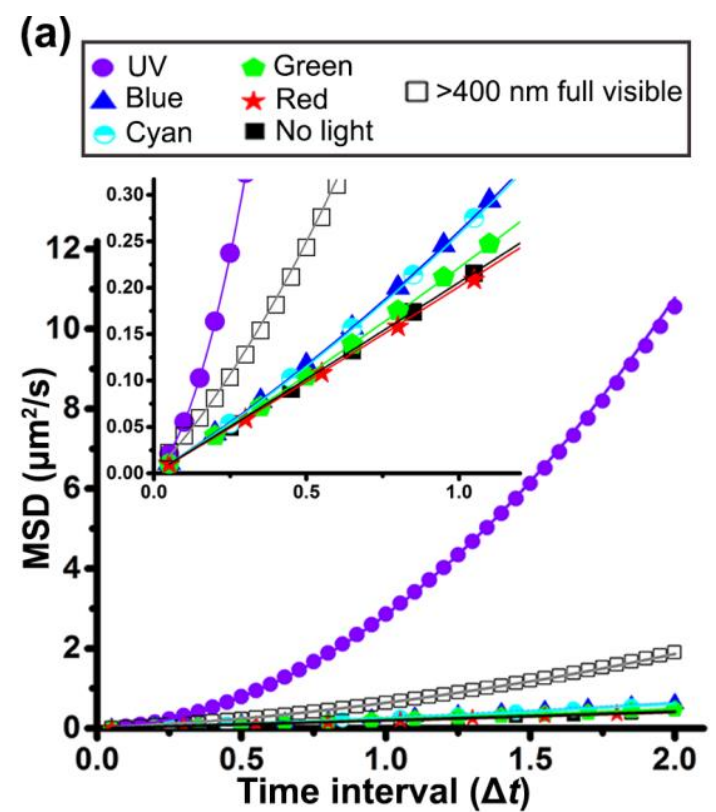

(b)

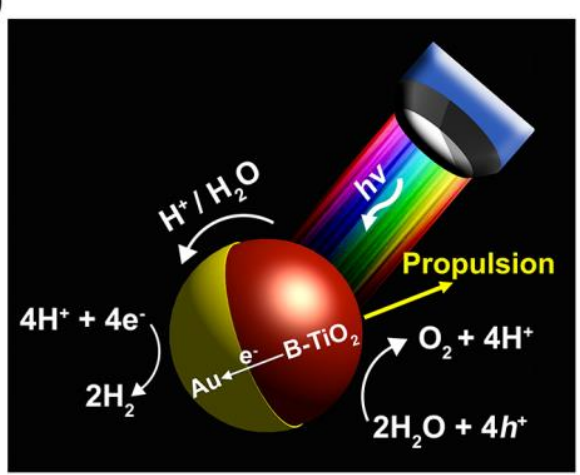

Figure 4. Microscopic analysis of the motion of $\mathrm{Au} / \mathrm{B}_{-} \mathrm{TiO}_{2}$ Janus micromotors driven in pure water. (a) MSD curves of $\mathrm{Au} / \mathrm{B}-\mathrm{TiO}_{2}$ Janus micromotors. Scatter points denote average MSD values and lines represent the displacement fitting. MSD curves were obtained from at least 14 independent moving motors. (b) A schematic describing a propulsion mechanism of $\mathrm{Au} / \mathrm{B}-\mathrm{TiO}_{2}$ Janus particles in pure water, proposed based on previous studies. ${ }^{16,40}$

Table 1. Translational diffusion coefficients and velocities of $\mathrm{Au} / \mathrm{B}-\mathrm{TiO}_{2} \mathrm{Janus}$ micromotors, obtained by fitting the MSD curves of Figure. 4. Note: The theoretical diffusivity of particles in a diameter of $3.5 \mu \mathrm{m}$ is $0.139 \mu \mathrm{m}^{2} / \mathrm{s}$.

\begin{tabular}{|c|c|c|c|c|c|c|c|}
\hline & UV & Blue & Cyan & Green & Red & $\begin{array}{c}\text { Full visible } \\
\text { light }\end{array}$ & No light \\
\hline $\begin{array}{c}D_{t 0} \\
\left(\mu \mathrm{m}^{2} / \mathrm{s}\right)\end{array}$ & 0.139 & 0.139 & 0.139 & 0.139 & 0.139 & 0.139 & 0.139 \\
\hline$D_{t}$ & 0.076 & 0.052 & 0.051 & 0.050 & 0.049 & 0.089 & 0.050 \\
$\left(\mu \mathrm{m}^{2} / \mathrm{s}\right)$ & $\pm 6.29 \mathrm{E}-4$ & $\pm 1.97 \mathrm{E}-4$ & $\pm 1.38 \mathrm{E}-4$ & $\pm 1.65 \mathrm{E}-4$ & $\pm 2.43 \mathrm{E}-4$ & \pm 0.0013 & $\pm 2.08 \mathrm{E}-4$ \\
\hline$v$ & 1.59 & 0.23 & 0.23 & 0.16 & 0.08 & 0.54 & 0.07 \\
$(\mu \mathrm{m} / \mathrm{s})$ & \pm 0.002 & \pm 0.002 & \pm 0.001 & \pm 0.002 & \pm 0.005 & \pm 0.006 & \pm 0.005 \\
\hline
\end{tabular}


Stop-go motion of $\mathrm{Au} / \mathrm{B}-\mathrm{TiO}_{2}$ micromotors, controlled by light on-off switching. Unlike conventional catalytic micromotors, which display uninterrupted motion in a fuel solution, photocatalytic micromotors can display stop-go motion by switching the light on and off. ${ }^{13-16}$ Stopgo motion of $\mathrm{Au} / \mathrm{B}-\mathrm{TiO}_{2}$ micromotors was demonstrated in 3 wt $\% \mathrm{H}_{2} \mathrm{O}_{2}$ solution with green light illumination $(540-550 \mathrm{~nm})$ during three on-off cycles. Very small displacements caused by Brownian motion were detected when the illumination was turned off (Figure 5a (i), (iii), and (v), and see the trajectory in Movie S5). In contrast, large displacements were observed when the illumination was turned on (Figure 5a (ii), (iv), and (iv)), and see the trajectory in Movie S5) The motor speed shows a noticeable increase from $\sim 2 \mu \mathrm{m} / \mathrm{s}$ to $\sim 8 \mu \mathrm{m} / \mathrm{s}$ in the presence of light (Figure $5 b)$.

(a)

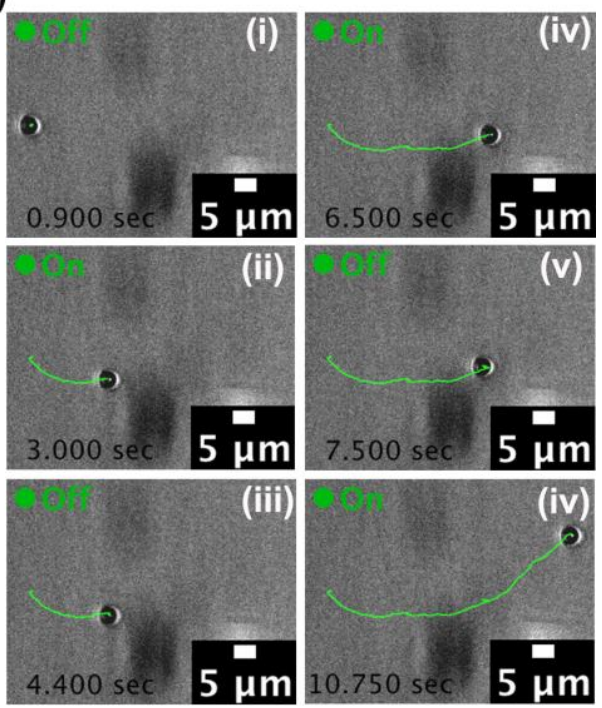

(b)

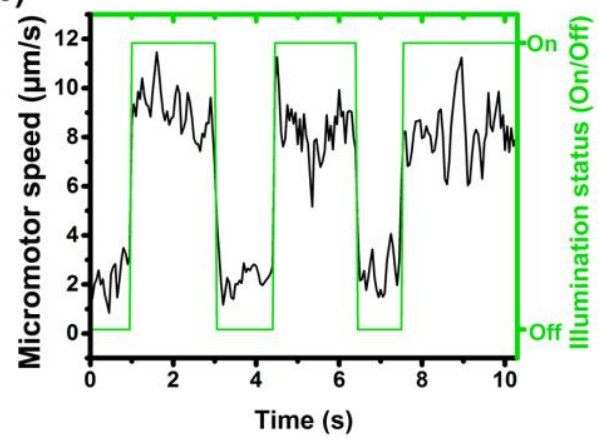

Figure 5. Stop-go motion of a $\mathrm{Au} / \mathrm{B}-\mathrm{TiO}_{2} \mathrm{Janus}$ micromotor, achieved by switching the propulsion light on and off in 3 wt \% $\mathbf{H}_{2} \mathrm{O}_{2}$. (a) Image sequences of the motion of a $\mathrm{Au} / \mathrm{B}-\mathrm{TiO}_{2} \mathrm{Janus}$ micromotor. (b) The corresponding motor speed (black line) with time to the input light signal (green line). 


\section{CONCLUSIONS}

Because of their narrow light absorption spectra, existing photocatalytic micromotors, such as $\mathrm{TiO}_{2}$, $\mathrm{Fe}_{2} \mathrm{O}_{3}, \mathrm{Cu}_{2} \mathrm{O}$, and $\mathrm{BiOI}$-based Janus motors, are limited to narrow ranges of wavelengths for locomotion because of their narrow light absorption spectra. In order to achieve a multi-wavelength light driven micromachine, $\mathrm{Au} / \mathrm{B}-\mathrm{TiO}_{2}$-based Janus microspheres with a broad light absorption range $(300-800 \mathrm{~nm})$ were developed. The $\mathrm{Au} / \mathrm{B}-\mathrm{TiO}_{2}$ Janus micromotors showed directional motion under multiple light wavelengths including UV (360-370 nm), blue (420-440 nm), cyan (460-495 nm), green (540-550 nm), and red (590-650 nm) light not only in $\mathrm{H}_{2} \mathrm{O}_{2}$ solution, but also in pure water. While experiments performed in pure water show very low motion speeds, a comparison of MSD curves between illuminated and control groups clearly indicate that photocatalytically driven propulsion occurs. Noticeably, the motor speed was shown to increase with a decrease in wavelength. We also observed a significant increase in motor speed when the micromotor was exposed to the full visible light spectrum $(\lambda>400 \mathrm{~nm})$. The maximum speed achieved under full visible light illumination in 3 wt $\% \mathrm{H}_{2} \mathrm{O}_{2}$ was $30.1 \pm 8.71 \mu \mathrm{m} / \mathrm{s}$. This high motor speed can be explained by the larger amount of electromagnetic energy available for propulsion.

\section{EXPERIMENTAL METHODS}

Synthesis of the $\mathrm{TiO}_{2}$ microspheres. The experimental procedure was adopted from $\mathrm{He}$ et $a l .{ }^{59}$ First, $1.33 \mathrm{ml}$ of titanium (IV) isopropoxide (Ti[OCH($\left.\left.\left(\mathrm{CH}_{3}\right)_{2}\right]_{4}\right), 99.999 \%$, Sigma-Aldrich) and $0.35 \mathrm{ml}$ of formic acid $(\mathrm{HCOOH}, \geq 95 \%$, Sigma-Aldrich) were rapidly dissolved in $30 \mathrm{ml}$ of absolute ethanol $\left(\mathrm{CH}_{3} \mathrm{CH}_{2} \mathrm{OH}, \geq 99.8 \%\right.$, Sigma-Aldrich). The solution was then stirred for 5 min in ambient air and transferred to a Teflon autoclave. Then, $\mathrm{TiO}_{2}$ microspheres were synthesized using the solvothermal method by placing the autoclave in an oven for $6 \mathrm{~h}$ at $150{ }^{\circ} \mathrm{C}$. The autoclave was 
then cooled to room temperature (RT) in ambient air. The resulting $\mathrm{TiO}_{2}$ microspheres were cleaned three times with ethanol and dried in ambient air for $12 \mathrm{~h}$ at $80^{\circ} \mathrm{C}$ to remove organic residuals.

Synthesis of the B-TiO 2 microspheres. The conversion of $\mathrm{TiO}_{2}$ to $\mathrm{B}-\mathrm{TiO}_{2}$ was achieved by thermally annealing the as-synthesized $\mathrm{TiO}_{2}$ microspheres in a ceramic chamber for $2 \mathrm{~h}$ at $400{ }^{\circ} \mathrm{C}$. Ramp-up rate of $1{ }^{\circ} \mathrm{C} / \mathrm{min}, 75^{\circ} \mathrm{C} / \mathrm{min}$, and $140{ }^{\circ} \mathrm{C} / \mathrm{min}$ were chosen to study the effect of the rampup rate on the conversion of $\mathrm{TiO}_{2}$ to $\mathrm{B}-\mathrm{TiO}_{2}$. While ramp-up rate of $1{ }^{\circ} \mathrm{C} / \mathrm{min}$ and $75^{\circ} \mathrm{C} / \mathrm{min}$ was obtained using a programmable electrical furnace (HT17/4, Nabertherm Co., Germany), the rampup rate of $140{ }^{\circ} \mathrm{C} / \mathrm{min}$ was achieved by placing the ceramic chamber on a $400{ }^{\circ} \mathrm{C}$ hot-plate.

Fabrication of the $\mathrm{Au} / \mathrm{B}-\mathrm{TiO}_{2}$ Janus micromotors. The $\mathrm{Au} / \mathrm{B}_{-} \mathrm{TiO}_{2}$ Janus micromotors were fabricated by evaporating a Au layer onto self-assembled $\mathrm{B}-\mathrm{TiO}_{2}$ microspheres. Briefly, a 2.5 cm x $2.5 \mathrm{~cm}$ silicon wafer was pre-cleaned by sonication in acetone $\left(\mathrm{CH}_{3} \mathrm{COCH}_{3}, \geq 99.9 \%\right.$, SigmaAldrich), isopropanol ethanol $\left(\mathrm{C}_{2} \mathrm{H}_{5} \mathrm{OH}, \geq 99.5 \%\right.$, Sigma-Aldrich), and distilled (DI) water each for $3 \mathrm{~min}$. Next, the surface of the Si wafer was rendered hydrophilic by dipping it in piranha solution $\left(\mathrm{H}_{2} \mathrm{SO}_{4}: \mathrm{H}_{2} \mathrm{O}_{2}=7: 3\right)$ for $24 \mathrm{~h}$. Then, the wafer was immersed in DI water. A B-TiO 2 suspension was prepared by adding $5 \mu \mathrm{g}$ of $\mathrm{B}-\mathrm{TiO}_{2}$ powder to $1 \mathrm{ml}$ of DI water. Subsequently, the suspension was sonicated for $30 \mathrm{~min}$ to prevent aggregation. $20 \mu \mathrm{g}$ of the $\mathrm{B}-\mathrm{TiO}_{2}$ suspension was then extracted and gently dispensed onto the water-immersed $\mathrm{Si}$ wafer. After $15 \mathrm{~min}$, the wafer was vertically positioned and carefully removed from the water at a withdrawal rate of $0.5 \mathrm{~mm} / \mathrm{sec}$. The wafer was

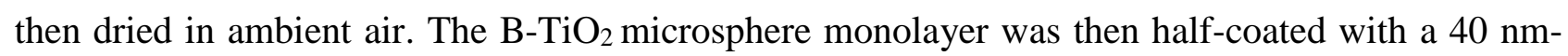
thick Au layer, by means of evaporation at a rate of $0.1 \AA$ A/s using a Plassys II evaporator (PlassysBestek Co., France). The $\mathrm{Au} / \mathrm{TiO}_{2}$ Janus microspheres used for control experiments were also prepared using the same procedure.

\section{Scanning electron microscopy (SEM) and energy-dispersive X-ray spectroscopy (EDX)}

imaging. Powder solutions of as-synthesized $\mathrm{TiO}_{2}$ microspheres, $\mathrm{B}-\mathrm{TiO}_{2}$ microspheres, and $\mathrm{Au} / \mathrm{B}$ $\mathrm{TiO}_{2}$ Janus micromotors were dispersed on a Si wafer and dried for SEM and EDX images. Images were obtained with an ULTRA 55 plus SEM (Carl Zeiss AG, Germany). 
X-ray photoelectron spectroscopy (XPS). XPS experiments were performed on a PHI 5500 Multitechnique System 465 (from Physical Electronics), with a monochromatic X-ray 466 source ( $\mathrm{Al} \mathrm{K \alpha}$ line of $1486.6 \mathrm{eV}$ energy and $350 \mathrm{~W}$ ), under ultrahigh vacuum and a pressure between $5 \times 10-9$ and $2 \times 10-8$ torr, placed perpendicular to the analyzer axis and calibrated using the $3 \mathrm{~d} 5 / 2$ line of $\mathrm{Ag}$, with a full width at half maximum of $0.8 \mathrm{eV}$. The analyzed area was a circle of $0.8 \mathrm{~mm}$ diameter for each sample. Charging effects were corrected by referencing the binding energies to those of the adventitious $\mathrm{C} 1 \mathrm{~s}$ line at $285 \mathrm{eV}$.

X-ray diffraction (XRD). Powder of as-synthesized $\mathrm{TiO}_{2}$ and $\mathrm{B}-\mathrm{TiO}_{2}$ microspheres were used for XRD measurement. The XRD measurement was conducted on a Bruker D8 Advance Xray diffractometer, equipped with a $\mathrm{Cu}$ target with the wavelength of $1.542 \AA$.

Diffuse Reflectance spectroscopy (DRS). Two DRS specimens were prepared by mixing the as-synthesized $\mathrm{TiO}_{2}$ and $\mathrm{B}-\mathrm{TiO}_{2}$ powders with a $\mathrm{BaSO}_{4}$ powder, both with a ratio of 1:1. Absorbance spectra of the two DRS specimens were obtained using a UV-Vis spectrophotometer (Cary 5000, Varian Co., US). The wavelength was scanned from 300 to $800 \mathrm{~nm}$.

Manipulation of micromotors. The motion of micromotors in aqueous solutions was investigated using an optical microscope (Olympus IX 81, Olympus Co., Japan) equipped with a mercury lamp (X-Cite 120, Excelitas Technologies, USA) and various filter cubes to obtain six different light emissions: 360-370 nm (UV), 420-440 nm (Blue), 460-495 nm (Cyan), 540-550 nm (Green), 590-650 nm (Red), and > $400 \mathrm{~nm}$ (Full visible spectrum). The six light emissions were used to actuate the micromotors and study the effect of wavelength on their propulsion speed; see the emission spectrums in Figure S7. In addition, various concentrations of $\mathrm{H}_{2} \mathrm{O}_{2}(3,0.3,0.03$ and 0 wt $\%$ ) were used to study the effect of $\mathrm{H}_{2} \mathrm{O}_{2}$ concentration on the speed of the micromotors. All motion was recorded using a charge-coupled device (CCD) video camera (XM 10, Olympus Co., Japan) at 20 frames-per-second with a magnification of $60 \mathrm{X}$ (Field number 22).

Emission spectrum and optical energy measurements. The spectrums of the six light emissions were measured using Avaspec-2048 (Avantes Co., Netherlands). The optical energies of 
the six different light emissions spectra were measured using a light power meter (13PEM001, Melles Griot Co., US). The measured energies are 1.2, 1.9, 2.7, 2.6, 1.7, and $21.5 \mathrm{~mW}$ for UV, blue, cyan, green, red, and full visible ( > $400 \mathrm{~nm}$ ) light, respectively. Since the beam diameter is $366 \mu \mathrm{m}$, obtained by dividing field number 22 with the magnification 60 , the calculated intensities are 1.14 , $1.80,2.56,2.46,1.61$, and $20.4 \mathrm{~W} / \mathrm{cm}^{2}$, for $\mathrm{UV}$, blue, cyan, green, red, and full visible ( > $400 \mathrm{~nm}$ ) light, respectively.

\section{ASSOCIATED CONTENT}

\section{Supporting Information}

The Supporting Information is available free of charge on the ACS Publications website.

Figure S1, S2, S3, S4, S5, S6, and S7, and Table S1 (PDF).

Movie S1. The motion of full visible light (> $400 \mathrm{~nm}$ )-driven (i) $\mathrm{Au} / \mathrm{B}-\mathrm{TiO}_{2}$ and (ii) $\mathrm{Au} / \mathrm{TiO}_{2}$ (control) Janus micromotor in $3 \mathrm{wt} \% \mathrm{H}_{2} \mathrm{O}_{2}$ (AVI).

Movie S2. Motion of $\mathrm{Au} / \mathrm{B}-\mathrm{TiO}_{2}$ Janus micromotors in 3 wt $\% \mathrm{H}_{2} \mathrm{O}_{2}$ under $\mathrm{UV}$, blue, cyan, green, and red light spectrum (AVI).

Movie S3. Motion of $\mathrm{Au} / \mathrm{B}-\mathrm{TiO}_{2}$ Janus micromotors in pure water under UV, blue, cyan, green, red, and full visible light spectrum, and in the absent of light (AVI).

Movie S4. Motion of $\mathrm{Au} / \mathrm{TiO}_{2}$ Janus micromotors (control sample) in pure water under UV, blue, cyan, green, red, and full visible light spectrum, and in the absent of light (AVI).

Movie S5. Stop /Go motion of $\mathrm{Au} / \mathrm{B}-\mathrm{TiO}_{2}$ Janus micromotors in 3 wt $\% \mathrm{H}_{2} \mathrm{O}_{2}$ under green light (AVI).

Code S1. MATLAB code for MSD curve and quadratic fitting for the translational diffusivity $\left(D_{t}\right)$ and the translational speed $(v)$ with an example trajectory.

This material is available free of charge via the Internet at http://pubs.acs.org.

\section{AUTHOR INFORMATION}




\section{Corresponding Author}

*E-mail: vidalp@ethz.ch

*E-mail: bnelson@ethz.ch

\section{Author Contributions}

B.J., B.J.N. and S.P. initiated the project. B.J. and S.P. designed the fabrication experiments. B.J., H.K., C.A., and F.M. fabricated the micromotors. B.J. and A.H. analyzed the motion of micromotors. B.J., A.H., H.K., C.A., S. C., E.P., R.B., J.S., S.S.L., B.J.N. and S.P. performed the analysis of the micromotors and provided theoretical discussion. B.J.N. and S.P. supervised the work and gave critical input. All authors contributed to discussions.

\section{Notes}

The authors declare no competing financial interest.

\section{ACKNOWLEDGEMENTS}

S.P. acknowledges financial support by the European Research Council Starting Grant "Magnetoelectric Chemonanomotorics for Chemical and Biomedical Applications (ELECTROCHEMBOTS)," by the ERC grant agreement n. 336456. B.J.N. acknowledges financial support by the Korea Evaluation Institute of Industrial Technology (KEIT) funded by the Ministry of Trade, Industry, and Energy (MOTIE) (NO. 10052980). C.A. acknowledges financial support by the Marie Skłodowska-Curie Innovative Training Network (H2020-MSCA-ITN-2014) under grant agreement 642642 (SELECTA). S.S.L acknowledges financial support by Global Research Laboratory (NRF-2015K1A1A2033054) through the National Research Foundation of Korea (NRF). Partial funding from the 2014-SGR-1015 project from the Generalitat de Catalunya, and the MAT2014-57960-C3-1-R project (co-financed by the Fondo Europeo de Desarrollo Regional, FEDER) from the Spanish Ministerio de Economía y Competitividad (MINECO) is also acknowledged. Dr. Eva Pellicer is grateful to MINECO for the "Ramon y Cajal" contract (RYC2012-10839). We especially thank Kakeru Fujiwara from the Particle Technology Laboratory (ETH 
Zürich) and Erdem Can Siringil from the Multi-Scale Robotics Lab (ETH Zürich) from the MultiScale Robotics Lab (ETH Zürich) for constructive discussions.

\section{REFERENCES}

(1) Sanchez, S.; Pumera, M. Nanorobots: The Ultimate Wireless Self-Propelled Sensing and Actuating Devices. Chem. Asian J. 2009, 4, 1402-1410.

(2) Sanchez, S.; Soler, L.; Katuri, J. Chemically Powered Micro- and Nanomotors. Angew. Chem. Int. Ed. Engl. 2015, 54, 1414-1444.

(3) Gibbs, J. G.; Kothari, S.; Saintillan, D.; Zhao, Y. P. Geometrically Designing the Kinematic Behavior of Catalytic Nanomotors. Nano Lett. 2011, 11, 2543-2550.

(4) Jang, B., et al. Catalytic Locomotion of Core-Shell Nanowire Motors. ACS Nano 2016, 10, 9983-9991.

(5) Kline, T. R.; Paxton, W. F.; Mallouk, T. E.; Sen, A. Catalytic Nanomotors: Remote-Controlled Autonomous Movement of Striped Metallic Nanorods. Angew. Chem. Int. Ed. 2005, 44, 744-746.

(6) Simmchen, J.; Katuri, J.; Uspal, W. E.; Popescu, M. N.; Tasinkevych, M.; Sanchez, S. Topographical Pathways Guide Chemical Microswimmers. Nat. Commun. 2016, 7, 10598.

(7) Solovev, A. A.; Smith, E. J.; Bof' Bufon, C. C.; Sanchez, S.; Schmidt, O. G. Light-Controlled Propulsion of Catalytic Microengines. Angew. Chem. Int. Ed. 2011, 50, 10875-10878.

(8) Ma, X.; Wang, X.; Hahn, K.; Sanchez, S. Motion Control of Urea-Powered Biocompatible Hollow Microcapsules. ACS Nano 2016, 10, 3597-3605.

(9) Wang, J.; Manesh, K. M. Motion Control at the Nanoscale. Small 2010, 6, 338-345.

(10) Zhang, Q.; Li, C.; Li, T. Rapid Photocatalytic Decolorization of Methylene Blue Using High Photon Flux UV/TiO2/H2O2 Process. Chem. Eng. J. 2013, 217, 407-413.

(11) Dahl, M.; Liu, Y.; Yin, Y. Composite Titanium Dioxide Nanomaterials. Chem. Rev. 2014, 114, 9853-9889. 
(12) Ni, M.; Leung, M. K. H.; Leung, D. Y. C.; Sumathy, K. A Review and Recent Developments in Photocatalytic Water-Splitting Using TiO2 for Hydrogen Production. Renew. Sust. Energ. Rev. 2007, 11, 401-425.

(13) Mou, F.; Kong, L.; Chen, C.; Chen, Z.; Xu, L.; Guan, J. Light-Controlled Propulsion, Aggregation and Separation of Water-Fuelled TiO2/Pt Janus Submicromotors and Their "on-theFly" Photocatalytic Activities. Nanoscale 2016, 8, 4976-4983.

(14) Mou, F.; Li, Y.; Chen, C.; Li, W.; Yin, Y.; Ma, H.; Guan, J. Single-Component TiO2 Tubular Microengines with Motion Controlled by Light-Induced Bubbles. Small 2015, 11, 2564-2570.

(15) Li, Y.; Mou, F.; Chen, C.; You, M.; Yin, Y.; Xu, L.; Guan, J. Light-Controlled Bubble Propulsion of Amorphous TiO2/Au Janus Micromotors. RSC Adv. 2016, 6, 10697-10703.

(16) Dong, R.; Zhang, Q.; Gao, W.; Pei, A.; Ren, B. Highly Efficient Light-Driven TiO2-Au Janus Micromotors. ACS Nano 2016, 10, 839-844.

(17) Dai, B.; Wang, J.; Xiong, Z.; Zhan, X.; Dai, W.; Li, C. C.; Feng, S. P.; Tang, J. Programmable Artificial Phototactic Microswimmer. Nat. Nanotechnol. 2016, 11, 1087-1092.

(18) Chen, C., et al. Light-Steered Isotropic Semiconductor Micromotors. Adv. Mater. 2017, 29, 1603374.

(19) Enachi, M.; Guix, M.; Postolache, V.; Ciobanu, V.; Fomin, V. M.; Schmidt, O. G.; Tiginyanu, I. Light-Induced Motion of Microengines Based on Microarrays of TiO2 Nanotubes. Small 2016, 12, 5497-5505.

(20) Moyses, H.; Palacci, J.; Sacanna, S.; Grier, D. G. Trochoidal Trajectories of Self-Propelled Janus Particles in a Diverging Laser Beam. Soft Matter 2016, 12, 6357-6364.

(21) Palacci, J.; Sacanna, S.; Abramian, A.; Barral, J.; Hanson, K.; Grosberg, A. Y.; Pine, D. J.; Chaikin, P. M. Artificial Rheotaxis. Sci. Adv. 2015, 1, e1400214.

(22) Palacci, J.; Sacanna, S.; Steinberg, A. P.; Pine, D. J.; Chaikin, P. M. Living Crystals of LightActivated Colloidal Surfers. Science 2013, 339, 936-940. 
(23) Palacci, J.; Sacanna, S.; Kim, S. H.; Yi, G. R.; Pine, D. J.; Chaikin, P. M. Light-Activated Self-Propelled Colloids. Phil. Trans. R. Soc. A 2014, 372, 20130372.

(24) Palacci, J.; Sacanna, S.; Vatchinsky, A.; Chaikin, P. M.; Pine, D. J. Photoactivated Colloidal Dockers for Cargo Transportation. J. Am. Chem. Soc. 2013, 135, 15978-15981.

(25) Zhou, D.; Li, Y. C.; Xu, P.; McCool, N. S.; Li, L.; Wang, W.; Mallouk, T. E. Visible-Light Controlled Catalytic Cu2O-Au Micromotors. Nanoscale 2017, 9, 75-78.

(26) Zhang, Q.; Dong, R.; Wu, Y.; Gao, W.; He, Z.; Ren, B. Light-Driven Au-WO3@C Janus Micromotors for Rapid Photodegradation of Dye Pollutants. ACS Appl. Mater. Interfaces 2017, 9 , 4674-4683.

(27) Dong, R.; Hu, Y.; Wu, Y.; Gao, W.; Ren, B.; Wang, Q.; Cai, Y. Visible-Light-Driven BiOIBased Janus Micromotor in Pure Water. J. Am. Chem. Soc. 2017, 139, 1722-1725.

(28) Ando, R.; Hama, H.; Yamamoto-Hino, M.; Mizuno, H.; Miyawaki, A. An Optical Marker Based on the UV-Induced Green-to-Red Photoconversion of a Fluorescent Protein. Proc. Natl. Acad. Sci. U.S.A. 2002, 99, 12651-12656.

(29) Sinha, R. P.; Häder, D.-P. UV-Induced DNA Damage and Repair: A Review. Photochem. Photobiol. Sci. 2002, 1, 225-236.

(30) Algvere, P. V.; Marshall, J.; Seregard, S. Age-Related Maculopathy and the Impact of Blue Light Hazard. Acta Ophthalmol. 2006, 84, 4-15.

(31) Godley, B. F.; Shamsi, F. A.; Liang, F. Q.; Jarrett, S. G.; Davies, S.; Boulton, M. Blue Light Induces Mitochondrial DNA Damage and Free Radical Production in Epithelial Cells. J. Biol. Chem. 2005, 280, 21061-21066.

(32) Wu, J.; Seregard, S.; Algvere, P. V. Photochemical Damage of the Retina. Surv. Ophthalmol. 2006, 51, 461-481.

(33) Bynoe, L. A.; Del Priore, L. V.; Hornbeck, R. Photosensitization of Retinal Pigment Epithelium by Protoporphyrin IX. Graefes Arch. Clin. Exp. Ophthalmol. 1998, 236, 230-233. 
(34) Rozanowska, M.; Sarna, T. Light-Induced Damage to the Retina: Role of Rhodopsin Chromophore Revisited. Photochem. Photobiol. 2005, 81, 1305-1330.

(35) Gourmelon, M.; Cillard, J.; Pommepuy, M. Visible Light Damage to Escherichia Coli in Seawater: Oxidative Stress Hypothesis. J. Appl. Bacteriol. 1994, 77, 105-112.

(36) Kielbassa, C.; Roza, L.; Epe, B. Wavelength Dependence of Oxidative DNA Damage Induced by UV and Visible Light. Carcinogenesis 1997, 18, 811-816.

(37) Jou, M.-J.; Jou, S.-B.; Guo, M.-J.; Wu, H.-Y.; Peng, T.-I. Mitochondrial Reactive Oxygen Species Generation and Calcium Increase Induced by Visible Light in Astrocytes. Ann. N. Y. Acad. Sci. 2004, 1011, 45-56.

(38) Hori, M.; Shibuya, K.; Sato, M.; Saito, Y. Lethal Effects of Short-Wavelength Visible Light on Insects. Sci. Rep. 2014, 4, 7383.

(39) Wang, R.; Sakai, N.; Fujishima, A.; Watanabe, T.; Hashimoto, K. Studies of Surface Wettability Conversion on TiO2 Single-Crystal Surfaces. J. Phys. Chem. B 1999, 103, 2188-2194.

(40) Chen, X.; Liu, L.; Huang, F. Black Titanium Dioxide (TiO2) Nanomaterials. Chem. Soc. Rev. 2015, 44, 1861-1885.

(41) Gupta, S. M.; Tripathi, M. A Review of TiO2 Nanoparticles. Chin. Sci. Bull. 2011, 56, 16391657.

(42) Mushtaq, F.; Asani, A.; Hoop, M.; Chen, X.-Z.; Ahmed, D.; Nelson, B. J.; Pané, S. Highly Efficient Coaxial TiO2-PtPd Tubular Nanomachines for Photocatalytic Water Purification with Multiple Locomotion Strategies. Adv. Funct. Mater. 2016, 26, 6995-7002.

(43) Jiang, X.; Zhang, Y.; Jiang, J.; Rong, Y.; Wang, Y.; Wu, Y.; Pan, C. Characterization of Oxygen Vacancy Associates within Hydrogenated TiO2: A Positron Annihilation Study. J. Phys. Chem. C 2012, 116, 22619-22624.

(44) Zheng, Z.; Huang, B.; Lu, J.; Wang, Z.; Qin, X.; Zhang, X.; Dai, Y.; Whangbo, M. H. Hydrogenated Titania: Synergy of Surface Modification and Morphology Improvement for Enhanced Photocatalytic Activity. Chem. Commun. 2012, 48, 5733-5735. 
(45) Li, G.; Zhang, Z.; Peng, H.; Chen, K. Mesoporous Hydrogenated TiO2 Microspheres for High Rate Capability Lithium Ion Batteries. RSC Adv. 2013, 3, 11507-11510.

(46) Xiao, X.; Zhang, W.-D. Facile Synthesis of Nanostructured BiOI Microspheres with High Visible Light-Induced Photocatalytic Activity. J. Mater. Chem. 2010, 20, 5866-5870.

(47) Pumera, M. Electrochemically Powered Self-Propelled Electrophoretic Nanosubmarines. Nanoscale 2010, 2, 1643-1649.

(48) Moran, J. L.; Posner, J. D. Electrokinetic Locomotion Due to Reaction-Induced Charge AutoElectrophoresis. J. Fluid Mech. 2011, 680, 31-66.

(49) Marine, N. A.; Wheat, P. M.; Ault, J.; Posner, J. D. Diffusive Behaviors of Circle-Swimming Motors. Phys. Rev. Lett. E 2013, 87, 052305.

(50) Lee, T. C.; Alarcon-Correa, M.; Miksch, C.; Hahn, K.; Gibbs, J. G.; Fischer, P. SelfPropelling Nanomotors in the Presence of Strong Brownian Forces. Nano Lett. 2014, 14, 2407-2412. (51) Demirok, U. K.; Laocharoensuk, R.; Manesh, K. M.; Wang, J. Ultrafast Catalytic Alloy Nanomotors. Angew. Chem. Int. Ed. Engl. 2008, 47, 9349-9351.

(52) Laocharoensuk, R.; Burdick, J.; Wang, J. Carbon-Nanotube-Induced Acceleration of Catalytic Nanomotors. ACS Nano 2008, 2, 1069-1075.

(53) Wang, Y.; Hernandez, R. M.; Bartlett, D. J.; Bingham, J. M.; Kline, T. R.; Sen, A.; Mallouk, T. E. Bipolar Electrochemical Mechanism for the Propulsion of Catalytic Nanomotors in Hydrogen Peroxide Solutions. Langmuir 2006, 22, 10451-10456.

(54) Boyce, J. M.; Havill, N. L.; Moore, B. A. Terminal Decontamination of Patient Rooms Using an Automated Mobile UV Light Unit. Infect. Control Hosp. Epidemiol. 2011, 32, 737-742.

(55) Riley, D. J.; Bavastrello, V.; Covani, U.; Barone, A.; Nicolini, C. An In-Vitro Study of the Sterilization of Titanium Dental Implants Using Low Intensity UV-Radiation. Dent. Mater. 2005, $21,756-760$. 
(56) Xu, C.; Yang, W.; Ren, Z.; Dai, D.; Guo, Q.; Minton, T. K.; Yang, X. Strong Photon Energy Dependence of the Photocatalytic Dissociation Rate of Methanol on TiO2(110). J. Am. Chem. Soc. 2013, 135, 19039-19045.

(57) Michalet, X. Mean Square Displacement Analysis of Single-Particle Trajectories with Localization Error: Brownian Motion in an Isotropic Medium. Phys. Rev. E 2010, 82, 041914.

(58) Nishikiori, H.; Qian, W.; El-Sayed, M. A.; Tanaka, N.; Fujii, T. Change in Titania Structure from Amorphousness to Crystalline Increasing Photoinduced Electron-Transfer Rate in Dye-Titania System. J. Phys. Chem. C 2007, 111, 9008-9011.

(59) He, K.; Zhao, G.; Han, G. Template-Free Synthesis of TiO2 Microspheres with Tunable Particle Size Via a Non-Aqueous Sol-Gel Process. CrystEngComm 2014, 16, 7881-7884.

\section{Table of Contents artwork}

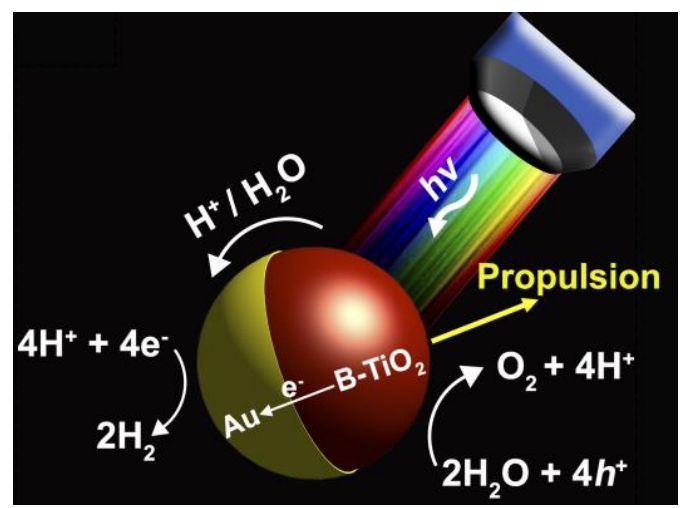

